\title{
PHASE DIAGRAMS AND THEIR APPLICATIONS TO Mg ALLOYS
}

Rainer Schmid-Fetzer '

\begin{abstract}
This work summarizes the basics of phase diagrams and their relation to the Calphad method. It is emphasized that the benefits of quantitative prediction of phase formation of selected multicomponent alloys under equilibrium and special off-equilibrium processing conditions require the development of reliable and consistent thermodynamic descriptions forming a Calphad-type thermodynamic database. The implications of intermetallic phases in multicomponent $\mathrm{Mg}$ alloys are explained for ternary $\mathrm{Mg}-\mathrm{Ce}-\mathrm{La} / \mathrm{Nd}$ alloys. An introduction to applications of this approach to phase formation in as-cast and heat treated $\mathrm{Mg}$ alloys is given and discussed in detail for the example of ternary Mg-Al-Zn alloys. The extension to truly multicomponent alloy systems and advanced kinetic calculations is briefly depicted.
\end{abstract}

Keywords: Calphad; Computational thermodynamics; Magnesium; Alloys; Phase diagrams.

\section{DIAGRAMAS DE FASES E SUAS APLICAÇÕES A LIGAS DE MAGNÉSIO}

\section{Resumo}

Este trabalho apresenta um sumário sobre diagramas de fases e suas relações com o método CALPHAD. Enfatiza-se que o benéfico de previsões quantitativas das fases formadas em ligas multicomponente em equilíbrio e em condições especiais de processamento fora do equilíbrio requer o desenvolvimento de descrições termodinâmicas confiáveis e consistentes, que formem um banco de dados termodinâmico do tipo CALPHAD. As implicações das fases intermetálicas nas ligas multicomponente a base de Mg são explicadas para ligas ternárias Mg-Ce-La/Nd. Uma introdução a aplicação deste enfoque a formação de fases em ligas brutas de fusão e tratadas termicamente é apresentada e discutida em detalhe em um exemplo de ligas ternárias $\mathrm{Mg}$-Al-Zn. A extensão a sistemas de ligas verdadeiramente multicomponente assim como cálculos cinéticos avançados é também apresentada, de forma resumida.

Palavras-chave: CALPHAD; Termodinâmica computacional; Magnésio; Ligas; Diagramas de fase.

\section{PHASE DIAGRAMS AND THE CALPHAD METHOD}

Phase diagrams are a cornerstone of knowledge in materials science and engineering. They are the perfect road map and starting point for designing all sorts of materials, such as alloys, ceramics, semiconductors, cement, concrete, or any material where the concept of phase is viable. They are also useful for optimization of closely related materials processes, such as melting, casting, crystal growth, joining, solid-state reaction, heat treatment / phase transformation, oxidation, vapor deposition, and so on.

Hand-plotted phase diagrams have proved to be most useful since more than a century. That dates back, for example, to the "first" T-x diagram for the Fe-C system presented in 1897 by Roberts-Austen [I], as explained in a historical paper [2]. Such diagrams, however, are superseded for current quantitative applications by phase diagrams based on thermodynamic calculations. There are two main reasons: (i) the need to address multicomponent systems for "real" materials, and (ii) the additional benefits of quantitative prediction of phase formation of a selected multicomponent alloy under equilibrium and special off-equilibrium processing conditions. Many of such applications are exemplified in a recent work [3], which is also a primer on "How to Read and Apply Phase Diagrams" in the current environment of powerful software packages.

This approach is one corner stone of Integrated Computational Materials Engineering (ICME). The key point, the application of "Calphad-generated" databases in Materials Science \& Engineering, is unique in the sense that it allows to proceed to truly multiphase and multicomponent phase equilibria. This goes beyond calculation of phase diagrams. It also enables simulation of phase formation in alloys, ceramics and other complex materials. Moreover, chemical reactions and processes may be simulated.

'Institute of Metallurgy, Clausthal University of Technology, Clausthal-Zellerfeld, Germany. E-mail: schmid-fetzer@tu-clausthal.de 
Central to this approach is the Calphad method [4,5]. The quintessence is depicted in Figure I. Thermodynamic data, such as enthalpy, heat capacity, vapor pressure, etc, are usually available from experimental studies and partly also from $a b$ intio studies. In a different class of data we may have phase equilibrium/transformation data at our disposal. These are currently only available experimentally with sufficient accuracy. The key point of the Calphad method is the consistent combination of these two classes of data. That is done by generation of a unique set of Gibbs energy functions, one for each phase $\varphi$, with the variables temperature, pressure and phase composition. The multiphase and multicomponent phase equilibria are then calculated by minimizing the Gibbs energy of the system at constant temperature, pressure and alloy composition. That is done by smart distribution of atoms on the available stable or metastable phases in any of the current thermodynamic software packages, Pandat [6], Thermocalc [7], or Factsage [8]. Thus, the formerly separated classes of data are combined into a consistent picture that also exploits the strong thermodynamic rules governing the interdependence of all data.

The generated "Calphad dataset" (thermodynamic description) of the system comprises, for each phase, both the Gibbs energy models and the pertinent thermodynamic parameters. In the whole, for large systems, this constitutes a thermodynamic database, such as the Mg alloy database in the focus of this work.

Also depicted in Figure I is the typical direct application. It encompasses the internally consistent calculation of any thermodynamic property and phase diagrams with the ability to extrapolate into unknown regions in temperature/composition space and into multicomponent systems. Moreover, crucial data concerning phase formation in the alloy system may be calculated or predicted. Specifically for magnesium alloys this approach has been demonstrated as a powerful tool in focused alloy design and process optimization [9-II].

\section{MULTICOMPONENT THERMODYNAMIC Mg ALLOY DATABASE}

Given the same thermodynamic database the various software packages mentioned above should arrive at the same results since they are all based on the Calphad method and minimization of Gibbs energy. That highlights the importance of the database used for achieving realistic results. Various databases may be available for the same material system with significantly different quality and modeling depth. With growing size of a database the key issues arising are consistency, coherency and quality assurance. These issues
Thermodynamic data

- Experimental

- Ab intio
Phase equilibrium data

- Experimental $\rightarrow$ Unique set of functions $G^{\varphi}\left(T, p, x_{i}\right)$

$\varphi=$ each stable/metastable phase in system

$\rightarrow G^{\text {system }}=\sum n^{\varphi} G^{\varphi}=$ minimum in equilibrium

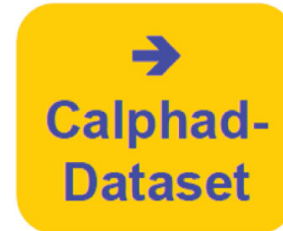

\section{Consistent calculation / prediction $\rightarrow$ Thermodynamic data $\quad \& \quad \rightarrow$ Phase diagram $\Rightarrow$ Phase formation \\ - Solidification (as-cast, Scheil simulation) \\ - Heat treatment (equilibrium) - Multicomponent alloys}

Figure I. Overview of the Calphad-method and specific applications in the simulation of phase formation of alloys. 
also concern extension, maintenance and updating of the database [10]. It has been shown [I I] that the key issue quality assurance involves addressing four quite distinct questions concerning the thermodynamic descriptions. It should be verified if these are correct, reasonable, accurate, and safe. In the following just one of these issues will be discussed, concerning intermetallic phases in multicomponent $\mathrm{Mg}$ alloys. Quite often these intermetallics are not simple stoichiometric compounds or phases with a simple binary solid solution range.

Some binary compounds may be coherent in ternary or higher order systems if crystallizing in the same structure. That can be exemplified by considering the two ternary systems $\mathrm{Mg}$-Ce-La and $\mathrm{Mg}$-Ce-Y. The binary phase diagrams $\mathrm{Mg}$-Ce and $\mathrm{Mg}$-La are shown in Figures 2 and 3, respectively, calculated using the thermodynamic descriptions given in refs

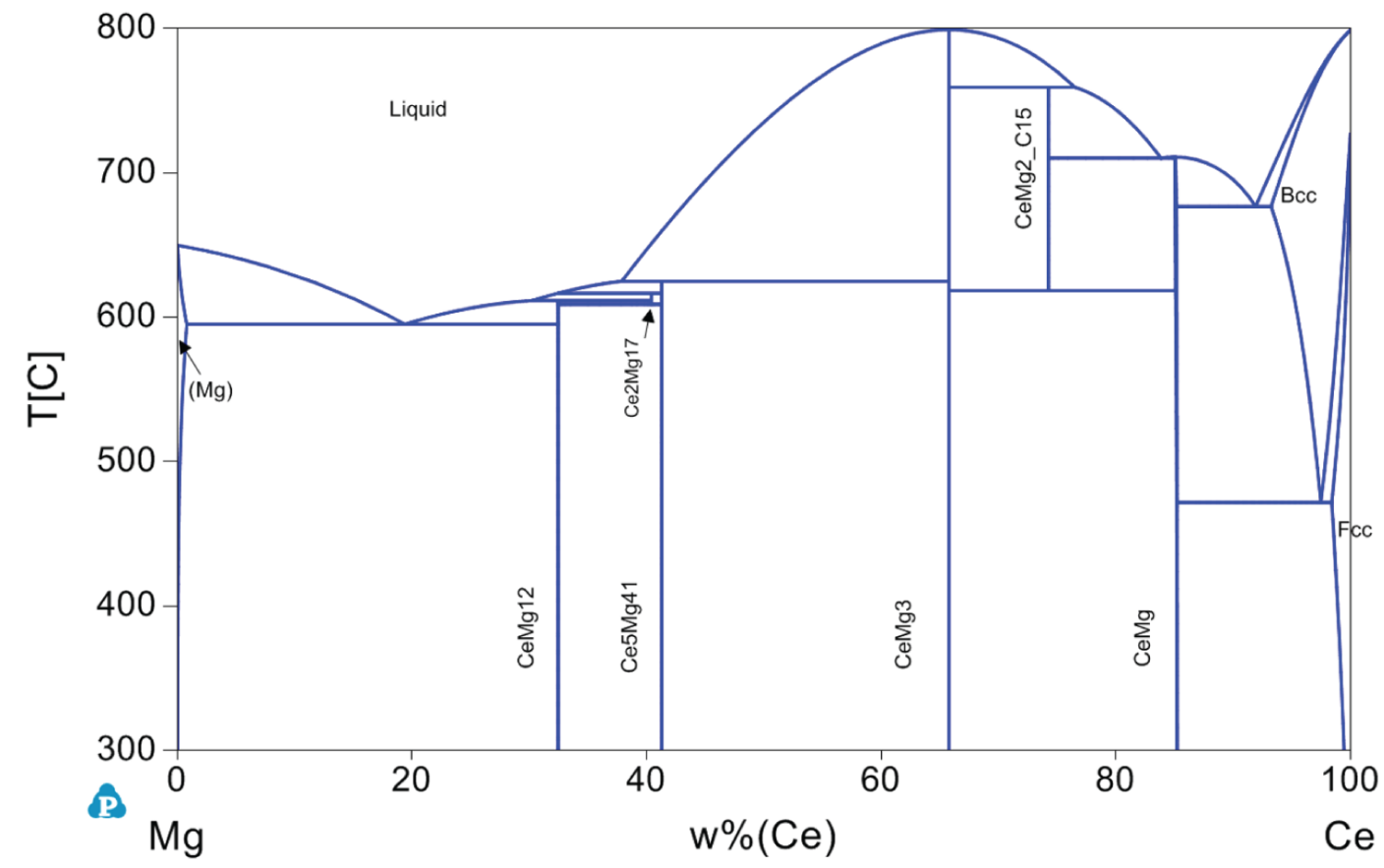

Figure 2. Calculated Mg-Ce phase diagram using the thermodynamic description of reference [14].

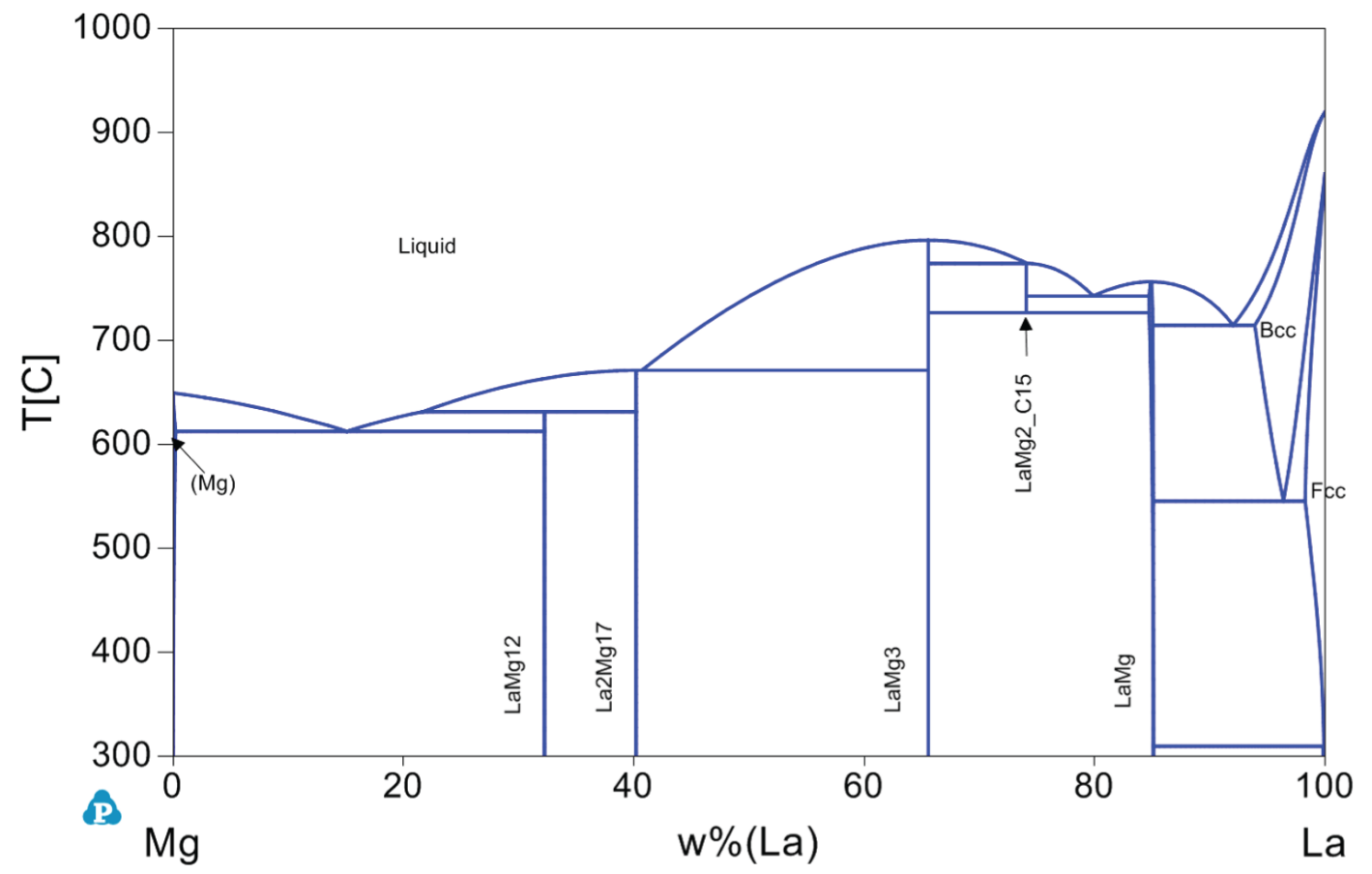

Figure 3. Calculated Mg-La phase diagram using the thermodynamic description of ref. [15]. 
$[12,13]$. All calculations in this work were performed using the software package Pandat (www.computherm.com), which offers specific advantages detailed in ref. [6]. The binary Ce-La edge system does not exhibit any intermetallic compounds but only the complete solid solution ranges joining the Dhcp, $\mathrm{Fcc}$, and Bcc crystal structures of pure $\mathrm{Ca}$ and $\mathrm{La}$.

In the ternary $\mathrm{Mg}-\mathrm{Ce}-\mathrm{La}$ phase diagram section at $500^{\circ} \mathrm{C}$ in Figure 4 only four of the five binary $\mathrm{Mg}-\mathrm{Ce}$ intermetallic compounds exist at the $\mathrm{Mg}$-Ce edge, these are $\mathrm{CeMg}_{12}, \mathrm{Ce}_{5} \mathrm{Mg}_{41}, \mathrm{CeMg}_{3}$, and $\mathrm{CeMg}$. Three of them, $\mathrm{CeMg}_{12}, \mathrm{CeMg}_{3}$, and $\mathrm{CeMg}$, have a stable counterpart at the $\mathrm{Mg}$-La edge, $\mathrm{LaMg}_{12}, \mathrm{LaMg}_{3}$, and $\mathrm{LaMg}$, respectively, with the same crystal structure. The protrusion of the binary compounds by solid solution into the ternary system is highlighted by red arrows in Figure 4, which is calculated from the data assessed in [15].

It is crucial that such phases with same crystal structure are unified in the thermodynamic modeling and that unique phase names are assigned. They must be consistent and should be concise and intuitive, such as $\mathrm{RMg}_{3}$ for the solid solution phase range $\mathrm{CeMg}_{3}-\mathrm{LaMg}_{3}$. That phase is modeled by intermixing of $\mathrm{Ce}$ and $\mathrm{La}$ on the first sublattice of the single phase $(\mathrm{Ce}, \mathrm{La})_{1} \mathrm{Mg}_{3}$. In the entire $\mathrm{Mg}$ database with 25 components, PanMg (www.computherm.com), the phase $\mathrm{RMg}_{3}$ with crystal structure $\mathrm{cFI} / 6-\mathrm{BiF}_{3}$ is modeled as $(\mathbf{C e}, \mathbf{G d}, \mathbf{L a}, \mathbf{N d}, \mathrm{Y})_{1}(\mathrm{Li}, \mathbf{M g}, \mathrm{Zn})_{3}$. The major constituents are highlighted by bold font whereas $\mathrm{Y}, \mathrm{Li}$, and $\mathrm{Zn}$ are minor constituents indicating that these elements exhibit limited solubility only in the phase $\mathrm{RMg}_{3}$. Therefore, $\mathrm{RMg}_{3}$ exists as stable compound in four of the binary edge systems, as $\mathrm{CeMg}_{3}, \mathrm{GdMg}_{3}, \mathrm{LaMg}_{3}$, or $\mathrm{NdMg}_{3}$, respectively.

The phase protrusion may, of course also be viewed vice versa from the $\mathrm{Mg}$ - $\mathrm{La}$ to the $\mathrm{Mg}$-Ce edge in Figure 4. In the ternary $\mathrm{Mg}$-Ce-La example - instead of modeling the six compounds $\mathrm{CeMg}_{12}, \mathrm{CeMg}_{3}, \mathrm{CeMg}, \mathrm{LaMg}_{12}, \mathrm{LaMg}_{3}$, and LaMg separately - only three (but more complex) phases, $\mathrm{RMg}_{12}, \mathrm{RMg}_{3}$, and $\mathrm{RMg}$, are assessed in the database. Therefore, the number of assessed phases may decrease with increasing modeling depth.

The phase diagram $\mathrm{Mg}-\mathrm{Ce}-\mathrm{Y}$ at $500^{\circ} \mathrm{C}$ in Figure 5 is calculated from the thermodynamic description assessed in [14]. Again, we see the protrusion of four binary $\mathrm{Mg}-\mathrm{Ce}$ intermetallic compounds into the ternary system. However, with dissolution of $\mathrm{Y}$ only the $\mathrm{CeMg}$ extends as $\mathrm{RMg}$ phase all the way to the $\mathrm{Mg}$-Y edge whereas the three compounds $\mathrm{CeMg}{ }_{12}, \mathrm{Ce}_{5} \mathrm{Mg}_{41}$, and $\mathrm{CeMg}_{3}$, show limited solubility only; the corresponding $\mathrm{Mg}-\mathrm{Y}$ compounds are not stable.

A special case is the $\mathrm{RMg}_{2}$ phase, which might be mistaken as a ternary phase if considering just the $500^{\circ} \mathrm{C}$ equilibria. However, it originates as the $\mathrm{CeMg}_{2}$ phase from the $\mathrm{Mg}$-Ce edge which is stable at higher temperature only in the binary system, see Figure 2, but stabilized by dissolution of $\mathrm{Y}$ in the $(\mathrm{Ce}, \mathrm{Y}) \mathrm{Mg}_{2}$ phase. Another peculiarity is that a phase with the same general composition $(\mathrm{Ce}, \mathrm{Y}) \mathrm{Mg}_{2}$ protrudes from the binary $\mathrm{Mg}-\mathrm{Y}$ edge. However, the binary compound $\mathrm{Mg}_{2} \mathrm{Y}$ possesses a different crystal structure,
$\mathrm{Cl} 4$, compared to the binary $\mathrm{CeMg}_{2}, \mathrm{Cl}$ 5. Therefore, even though the sublattice description ( $\mathrm{Ce}, \mathrm{Y}) \mathrm{Mg}_{2}$ is formally the same, these are modeled as separate phases and named separately as $\mathrm{RMg}_{2}(\mathrm{Cl} 5)$ and $\mathrm{Mg}_{2} \mathrm{Y}(\mathrm{Cl} 4)$. In the entire $\mathrm{Mg}$

Table I. Phase names and models of two selected intermetallic phases in the database PanMg.

\begin{tabular}{ll}
\hline \multicolumn{1}{c}{ Phase name } & \multicolumn{1}{c}{ Phase model } \\
\hline $\mathrm{RMg}_{2}(\mathrm{Cl} 5)$ & $(\mathbf{C e}, \mathbf{G d}, \mathrm{La}, \mathbf{N d}, \mathbf{Y})_{1}(\mathbf{A l}, \mathrm{Cu}, \mathbf{M g}, \mathrm{Zn})_{2}$ \\
$\mathrm{Mg}_{2} \mathrm{Y}(\mathrm{Cl} 4)$ & $\left.(\mathbf{M g})_{2}(\mathrm{Ce}, \mathrm{Gd}, \mathrm{Nd}, \mathbf{Y})\right)_{1}$ \\
\hline
\end{tabular}

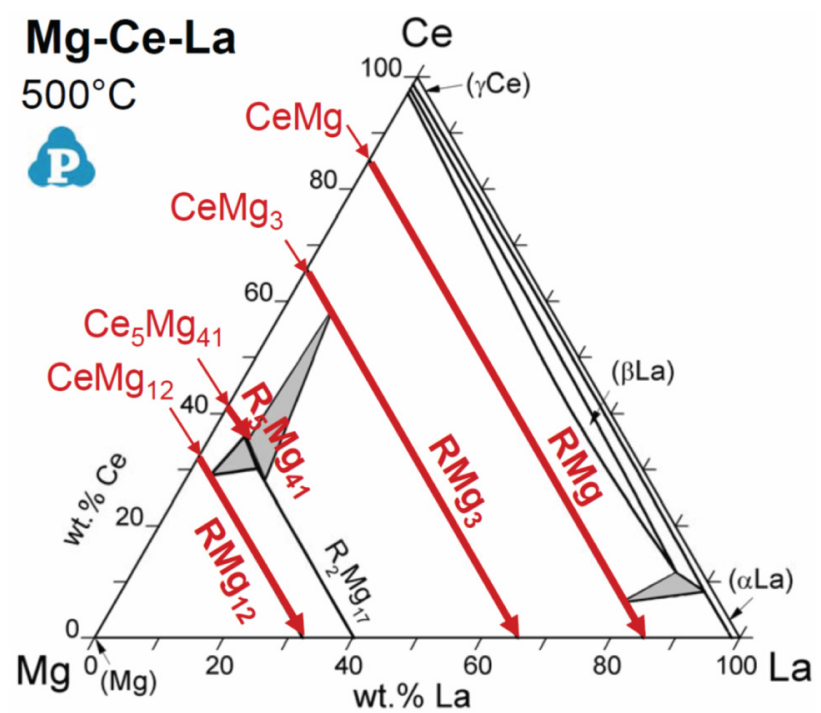

Figure 4. Calculated $\mathrm{Mg}$-Ce-La isothermal phase diagram section at $500^{\circ} \mathrm{C}$. The protrusion of four binary $\mathrm{Mg}$-Ce intermetallic compounds in the ternary system is highlighted by red arrows.

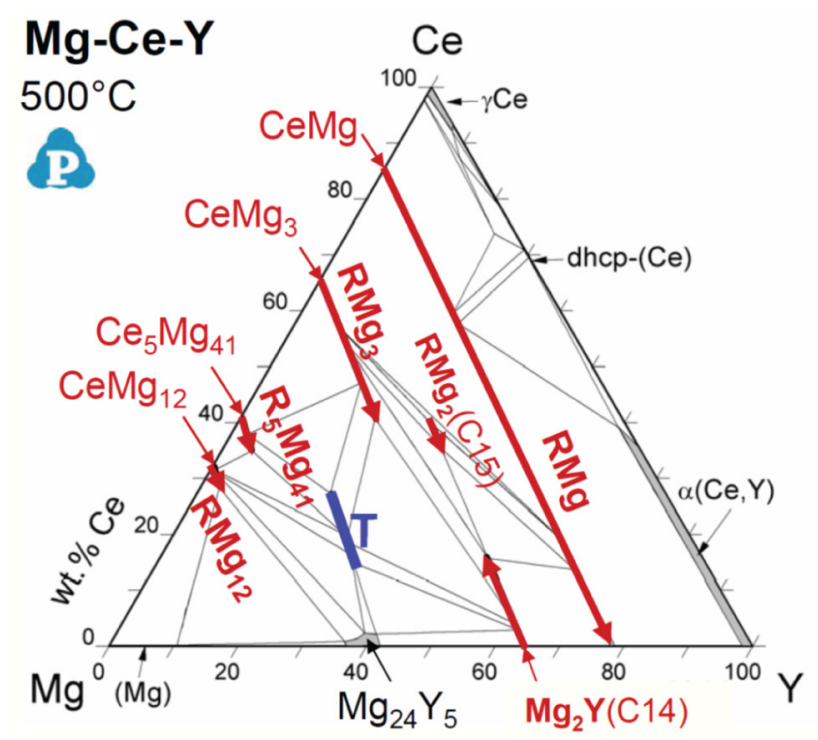

Figure 5. Calculated $\mathrm{Mg}-\mathrm{Ce}-\mathrm{Y}$ isothermal phase diagram section at $500^{\circ} \mathrm{C}$. The protrusion of the five binary $\mathrm{Mg}$-Ce intermetallic compounds in the ternary system is highlighted by red arrows. 
database these two phases are modeled as given in Table I with major constituents highlighted by bold font:

Therefore, $\mathrm{RMg}_{2}(\mathrm{Cl} 5)$ is stable in eight binary systems as $\mathrm{CeMg}_{2}, \mathrm{LaMg}_{2}, \mathrm{NdMg}_{2}, \mathrm{CeAl}_{2} \mathrm{GdAl}_{2}, \mathrm{LaAl}_{2}, \mathrm{NdAl}_{2}, \mathrm{YAl}_{2}$. By contrast, $\mathrm{Mg}_{2} \mathrm{Y}(\mathrm{Cl} 4)$ is stable only in the binary $\mathrm{Mg}-\mathrm{Y}$ system as $\mathrm{Mg}_{2} \mathrm{Y}$ with limited solubility of $\mathrm{Ce}, \mathrm{Gd}$, and $\mathrm{Nd}$.

This leaves the phase T, marked blue in Figure 5, as the only truly ternary phase in the $\mathrm{Mg}$-Ce-Y system. It does not connect to any binary edge, not even at temperatures different from $500^{\circ} \mathrm{C}$. This example highlights that phase identification in the microstructure of such Mg alloys based only on local composition analysis, such as SEM/EDS or microprobe, may be hard to interpret without viewing the wider picture of the entire phase diagram.

\section{APPLICATIONS TO AS-CAST AND HEAT TREATED ALLOYS}

The most prominent example of applying Calphad-generated databases in Materials Science \& Engineering is the approximate prediction of phase formation in heat treated and as-cast alloys. That is possible by assuming that the heat treated constitution may be close to the equilibrium one which is directly calculated from the thermodynamic equilibrium for any multicomponent alloy covered by the available database. By contrast, the phases actually observed in the as-cast state of alloys are often different, presenting an off-equilibrium state. That may be related to relatively slow solid-state diffusion compared to the solidification rate.

Under these conditions the so-called "Scheil approximation" is widely applied as a much better description. The Scheil approximation originated from the classic work of Scheil [15]. In the classic "Scheil equation" the distribution coefficient, $k_{0}$, is assumed to be constant. That concept is superseded by using numerical calculations with exact tie lines from thermodynamic equilibrium. These numerical "Scheil algorithms" use three assumptions, (i) Local equilibrium at the liquid / solid interface prevails; (ii) The liquid phase is perfectly mixed; (iii) No solid-state diffusion occurs during and after solidification. The key distinction between the equilibrium and Scheil approximation is, thus, the assumed infinitely fast solid-state diffusion in the equilibrium case and the completely blocked solid-state diffusion in the Scheil approximation. A more detailed discussion of the Scheil approximation in the context of numerical "Scheil algorithms" is given in ref. [3].

The different features of these two limiting cases, the equilibrium and Scheil approximation, respectively, will be exemplified for the solidification simulation of a ternary Mg-Al9Zn I (wt.\%) alloy. That is the nominal alloy composition of the important magnesium casting alloy AZ9I. At this point it is noted that - for the wider picture and related alloys - it is useful to know and understand the ternary $\mathrm{Mg}-\mathrm{Al}-\mathrm{Zn}$ phase diagram, as shown later. However, the good news for users not acquainted with the phase diagram is that only the easy-to-read phase fraction charts of the Mg-Al9Zn I alloy need to be calculated (as easily done in Pandat) and reviewed.

For equilibrium conditions, this phase fraction chart is given with logarithmic scale in Figure 6. Starting with the completely molten alloy at $700^{\circ} \mathrm{C}$ the liquidus point is attained at $600^{\circ} \mathrm{C}$. Upon further cooling the liquid phase fraction, $f$ Liquid, moves from I to zero at the solidus temperature of $446^{\circ} \mathrm{C}$. Concurrently, the solid phase $(\mathrm{Mg})$ crystallizes and its fraction grows from zero to I. Thus, solidification terminates without precipitation of any secondary phase. The reason is simply that all the alloying components can be dissolved in the $(\mathrm{Mg})$ solid solution, attaining exactly $\mathrm{Mg}-\mathrm{Al} \mathrm{ZnI}$ at the solidus point, where the last droplet of equilibrated liquid has the composition Mg-Al23.6Zn I0.3. The completely solid single-phase $(\mathrm{Mg})$ region exists from $446-381^{\circ} \mathrm{C}$ for this alloy, as seen in Figure 6. Below that (solvus) temperature, the secondary phase $\gamma$ precipitates in a solid-state reaction from the $(\mathrm{Mg})$ matrix phase.

For Scheil conditions the phase fraction chart is given in Figure 7. The liquidus point is again at $600^{\circ} \mathrm{C}$ because supercooling effects are not considered in the Scheil approximation. However, the liquid phase fraction does not come to zero during the primary solidification of the $(\mathrm{Mg})$ solid solution phase. This significant distinction to the equilibrium solidification arises because much less of the alloying components can be dissolved in the $(\mathrm{Mg})$ phase due to the blocked back diffusion. The core of the first crystal, formed at $600^{\circ} \mathrm{C}$ from $\mathrm{Mg}-\mathrm{Al} 9 \mathrm{ZnI}$, remains frozen at the low composition of Mg-Al2.6Zn0.06. A remarkable composition gradient is formed in the growing $(\mathrm{Mg})$ phase from that core crystal to the last layer solidified with composition

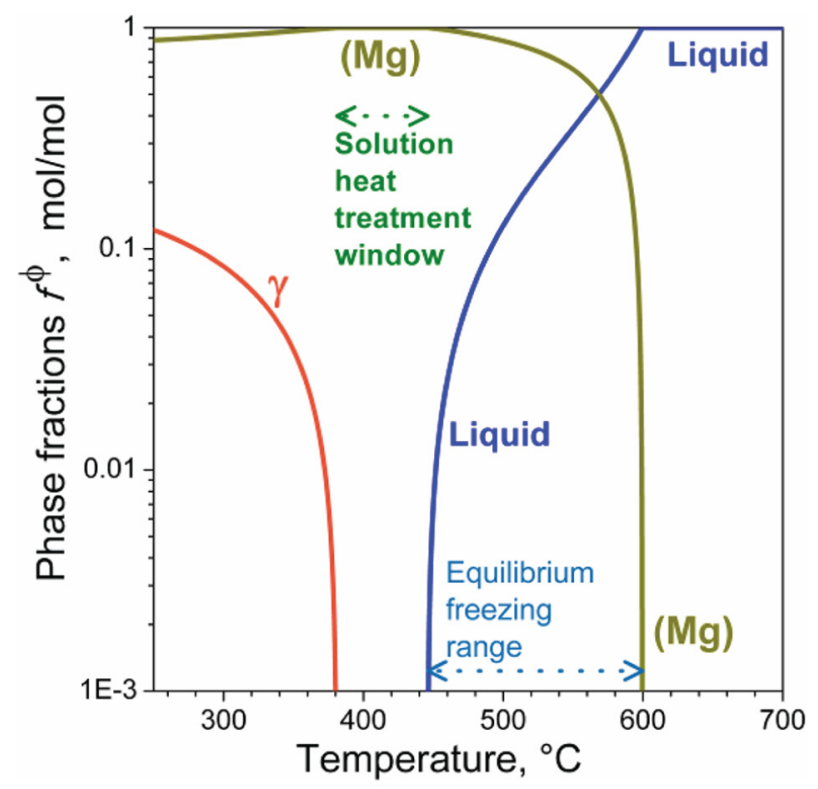

Figure 6. Phase fractions evolving during equilibrium solidification simulation of a ternary Mg-Al9Zn I (wt.\%) alloy. 
Mg-All I.7Zn0.5 at $429^{\circ} \mathrm{C}$. At that point $f^{(\mathrm{Mg})}=0.834$ and $f^{\text {Liquid }}=0.166$, seen at the bend in the liquid fraction curve in Figure 7. Subsequently, the secondary phase $\gamma$ crystallizes jointly with $(\mathrm{Mg})$ from the melt in the monovariant reaction $\mathrm{L} \rightarrow(\mathrm{Mg})+\gamma$ from $429-365.34^{\circ} \mathrm{C}$.

The next break point in Figure 7 occurs at $365.34^{\circ} \mathrm{C}$ (liquid composition Mg-All.7Zn34.3) where only a small amount of residual liquid is left, $f$ Liquid $=0.004$, and the accumulated solid fractions are $f^{(\mathrm{Mg})}=0.886$, and $f^{\gamma}=0.110$. At that point the invariant reaction $L+\gamma=(\mathrm{Mg})+\varphi$ is encountered at $365.34^{\circ} \mathrm{C}$. This is a ternary transition-type reaction where the formation of the product phases $(\mathrm{Mg})+\varphi$ would form a solid-state diffusion barrier. Therefore, this type of reaction cannot proceed under Scheil conditions, it is overrun. Solidification simply proceeds with the residual liquid, now saturated with $(\mathrm{Mg})+\varphi$. The amount of $\gamma$ remains constant, that phase is frozen-in with $f^{\gamma}=0.110$. It will be overgrown by the following crystallizing phases, thus, loosing contact to the moving liquid/solid phase boundary. That is typical for such unreacted remains, or peritectic phases, often producing a characteristic as-cast microstructure.

The subsequent solidification $\mathrm{L} \rightarrow(\mathrm{Mg})+\varphi$ occurs from 365.34-337.67 ${ }^{\circ} \mathrm{C}$, producing the small fraction of $\varphi, f^{\varphi}=0.002$. The next invariant reaction, $\mathrm{L}+\varphi=(\mathrm{Mg})+\tau$, at $337.67^{\circ} \mathrm{C}$, is again a transition-type reaction that will be overrun in the Scheil simulation, the phase fractions do not change at this invariant point. Solidification proceeds with the residual liquid, $f^{\text {Liquid }}=8.7 \cdot 10^{-4}$, along a short range of $L \rightarrow(M g)+\tau$. Finally, the ternary eutectic $\mathrm{L}=(\mathrm{Mg})+\tau+\mathrm{MgZn}$ is encountered at $336.77^{\circ} \mathrm{C}$. This decomposition-type reaction proceeds fully, thus terminating solidification. The residual ternary eutectic liquid, $f^{\text {Liquid }}=7.9 \cdot 10^{-4}$, decomposes completely to produce

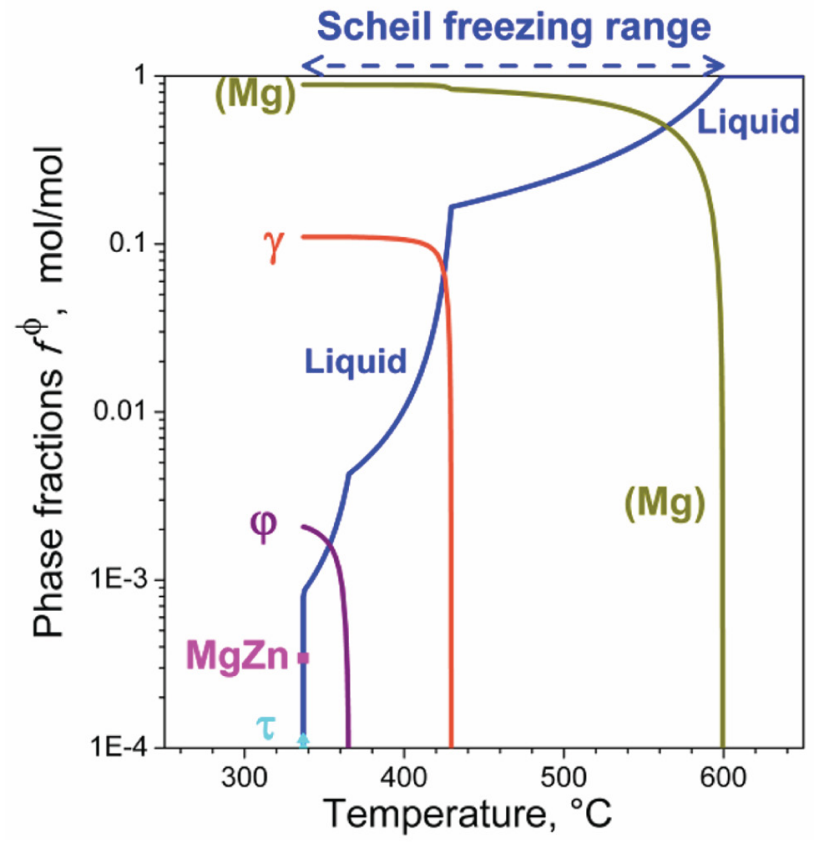

Figure 7. Phase fractions evolving during Scheil solidification simulation of a ternary $\mathrm{Mg}-\mathrm{Al} 9 \mathrm{ZnI}$ alloy. some more $(\mathrm{Mg})$ and $\tau$ and the additional phase $\mathrm{MgZn}$. At this point, and at $T<336.77^{\circ} \mathrm{C}$, the alloy Mg90Al9Zn I is composed of $f^{(\mathrm{Mg})}=0.887, f^{\gamma}=0.110, f^{\varphi}=0.002$, $f^{\tau}=1.1 \cdot 10^{-4}$, and $f^{\mathrm{MgZn}}=3.4 \cdot 10^{-4}$. These values are shown in Figure 7 at the end of the various phase fraction curves and the point for $\mathrm{MgZn}$. The predicted as-cast constitution of alloy Mg-Al9Zn I comprises five solid phases: (Mg), $\gamma, \varphi$, $\tau$, and $\mathrm{MgZn}$ - clearly off-equilibrium for a ternary alloy.

This Scheil simulation of the as-cast constitution is complemented by the information about the given sequence of phase precipitation, providing important clues on the schematic alloy microstructure with primary, secondary etc. phase formation. Moreover, the compositions of all phases are also obtained and could be plotted together with the phase fractions as function of the local phase formation temperature, revealing the expected segregation within the solid solution phases. In addition, the "Scheil solidus" at $336.77^{\circ} \mathrm{C}$ is a good approximation of the incipient melting temperature of the as-cast alloy. That is an important temperature limit during extrusion or other hot forming processes.

Heating at $336^{\circ} \mathrm{C}$ will eventually produce the equilibrium constitution $(\mathrm{Mg})+\gamma$ with $f^{(\mathrm{Mg})}=0.95$ and $f^{\gamma}=0.05$, see Figure 6, by dissolution of the non-equilibrium phases $\varphi$, $\tau, M g Z n$ and leveling out the segregation in the solution phases. This also suggests a safe two-step heat treatment process, a first step slightly below $336^{\circ} \mathrm{C}$ to avoid incipient melting and removing the low melting ternary eutectic, and a second step inside the solution heat treatment window, shown in Figure 6, to produce a fully single-phase $(\mathrm{Mg})$ alloy. The example in Figure 7 has been discussed until the termination of solidification in the ternary eutectic with $f^{\text {Liquid }}=0$ to highlight all aspects of the different reaction types in relation to the solidification path. Care should be taken for realistic applications if the residual liquid fraction becomes very small. It is often advisable to consider an arbitrary cut-off limit at e.g. $f^{\text {Liquid }}=0.005$ or $0.5 \%$ of residual liquid.

For general practical applications of such phase fraction charts the solution heat treatment window indicated for this alloy in Figure 6 from $446-381^{\circ} \mathrm{C}$ in the single-phase $(\mathrm{Mg})$ region is important. The relatively narrow equilibrium freezing range, however, is often a bad approximation for the casting process. The better approximation is the Scheil freezing range indicated in Figure 7.

It is important that the same easy-to-read phase fraction charts can be calculated using Pandat for any multicomponent alloy. An example is given in Figure 8 for the six-component alloy Mg-3Zn0.5Ag0.25Ca0. $15 \mathrm{Mn} 0.5 \mathrm{Zr}$ (wt.\%). This calculation was performed [16] in a work developing the design strategy for microalloyed ultra-ductile magnesium alloys. Together with Scheil simulations for this and a second alloy the processing steps for casting and hot extrusion could be optimized to produce very fine grains $(<10 \mu \mathrm{m})$, and high ductility (elongation to fracture of up to $30 \%$ ) at moderate strength or high strength (ultimate tensile strength of up to $350 \mathrm{MPa}$ ) at reasonable ductility [17]. 
As mentioned above it is not mandatory to know or understand the multicomponent phase diagram if only the easy-to-read phase fraction charts are studied. However, it is most useful to know and understand the phase diagram in conjunction with the phase fraction charts to gain a wider view for related alloys in the system. This is demonstrated for the ternary $\mathrm{Mg}-\mathrm{Al}-\mathrm{Zn}$ phase diagram in Figure 9, the $\mathrm{Mg}$-rich part of the calculated $\mathrm{Mg}$-Al-Zn liquidus projection. Such partial phase diagrams are best plotted in rectangular coordinates, which are easier to read as compared to the triangular diagram used for the full composition ranges.

The overall composition of the Mg-Al9ZnI alloy studied in Figures 6 and 7 is plotted as the starting point in Figure 9. The blue curve is the solidification path under equilibrium conditions, showing the composition variation of the residual liquid phase while its fraction shrinks from I to zero. The liquid composition moves from $\mathrm{Mg}-\mathrm{Al} 9 \mathrm{ZnI}$ at the liquidus temperature of $600^{\circ} \mathrm{C}$ to $\mathrm{Mg}-\mathrm{Al} 23.6 \mathrm{Zn} 10.3$ where it stops at the solidus temperature of $446^{\circ} \mathrm{C}$. The solidification path in Figure 9 is strongly curved to the $\mathrm{Zn}$-rich side in the final stage. That is because the $L+(M g)$ tie lines, passing through the fixed $\mathrm{Mg}-\mathrm{Al} 9 \mathrm{ZnI}$ point, rotate significantly with decreasing temperature.

The red curve in Figure 9 is the solidification path under Scheil conditions. It starts at the same liquidus point as in the equilibrium case but then differs significantly. While crystallizing primary $(\mathrm{Mg})$ the liquid composition moves in an almost straight line from $\mathrm{Mg}-\mathrm{Al} / \mathrm{Zn} \mathrm{I}$ to $\mathrm{Mg}-\mathrm{Al} 29.7 \mathrm{Zn} 5.0$ where it hits the monovariant line of double saturation, $\mathrm{L}+(\mathrm{Mg})+\gamma$ at $429^{\circ} \mathrm{C}$. That point corresponds to the first break point in the liquid fraction curve in Figure 7. At that point, the solidification path in Figure 9 also shows a break, after which it continues with decreasing Al-content. The second break point in Figure 7 at $365.34^{\circ} \mathrm{C}$ occurs where the solidification path in Figure 9 hits the invariant reaction $\mathrm{L}+\gamma=(\mathrm{Mg})+\varphi$. The red curve in Figure 9 continues along the reactions $L \rightarrow(M g)+\varphi, L+\varphi=(M g)+\tau$ (overrun), $\mathrm{L} \rightarrow(\mathrm{Mg})+\tau$, and ends in the terminating ternary eutectic $\mathrm{L}=(\mathrm{Mg})+\tau+\mathrm{MgZn}$.

Quantitatively, the partial freezing range near termination of solidification, the terminal freezing range (TFR) [I8] may be obtained from Scheil simulation. For example, this value may be taken from 88 to $98 \%$ fraction solid, indicating the TFR of the "almost" last $10 \%$ of solidifying liquid. This value is more relevant than the one for the "last 10\%" because of the limitations of the Scheil approximations in the last $1 \%$ or $2 \%$ of liquid fraction. Secondly, a small TFR should be beneficial in order to avoid hot tearing. It is less useful to account for a limit of $0 \%$ liquid in that application instead of a small but not harmful residual limit. The experimentally observed hot-tearing susceptibility (HTS) has been successfully correlated to the phase diagram features of $\mathrm{Mg}$-Al-Ca alloy castings: wide freezing range and low eutectic content result in higher HTS [17]. Scheil simulations have been used to reveal that the HTS increases with increasing fraction solid at the end of primary solidification of Mg-Al-Sr alloys [19].

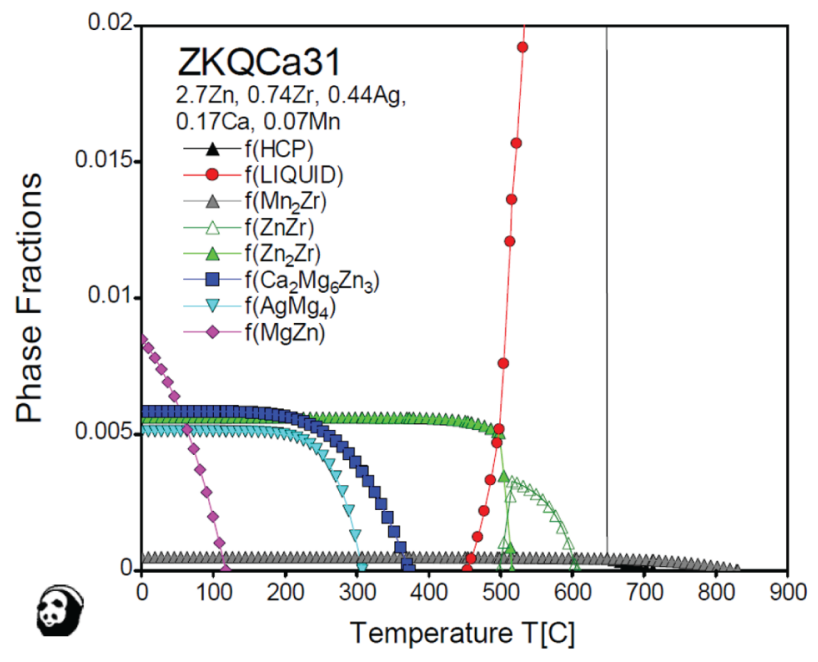

Figure 8. Calculated equilibrium phase fractions of the six-component alloy $\mathrm{Mg}-3 \mathrm{Zn} 0.5 \mathrm{Ag} 0.25 \mathrm{Ca} 0.15 \mathrm{Mn} 0.5 \mathrm{Zr}$ (wt.\%).

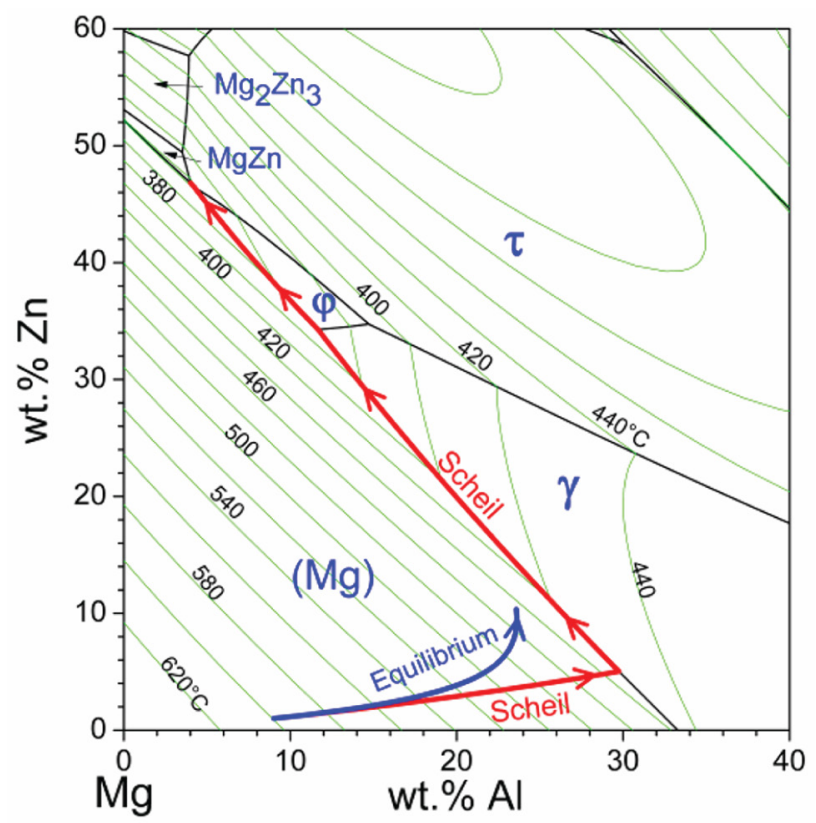

Figure 9. Mg-rich part of the Mg-Al-Zn liquidus projection. The solidification paths of alloy Mg-Al9ZnI are superimposed for equilibrium and Scheil simulation, respectively.

This powerful tool was also used to predict and reduce liquation-cracking susceptibility during welding of Al alloys with different filler alloys by Scheil simulation of the respective solidified fractions [20].

\section{CONCLUSIONS}

The approximate prediction of phase formation in heat treated and as-cast alloys using equilibrium and Scheil simulation is currently one work horse of ICME because "only" the thermodynamic Calphad-type database is required but 
no kinetic data whatsoever. Such kinetic data are generally scarce, hindering more advanced calculations. This field is rapidly evolving, though; advanced kinetic calculations are consistently build upon proper knowledge of the thermodynamic descriptions. An example is the concurrent nucleation and growth of precipitates using a Kampmann-Wagner approach to simulated key microstructure properties, such as the number density and particle size evolving in time. These calculations may be done using the PanPrecipitation module of Pandat software, as demonstrated for a Mg alloy [2I].
Another aspect that may be considered - beyond phase diagrams and thermodynamics - is the role of crystallography combined with thermodynamics on phase selection during solidification and heat treatment. That was demonstrated for binary magnesium - rare earth ( $\mathrm{Ce}$ or $\mathrm{Nd}$ ) alloys [22]. As a concluding remark it is emphasized that for truly multicomponent material systems the successful tools for predictive simulation of phase formation should all be based on reliable thermodynamic descriptions. That is sufficient for the work horse of equilibrium and Scheil simulations and may be amended by kinetic data for more advanced simulations.

\section{REFERENCES}

I Roberts-Austen WC. Fourth report to the alloys research committee. Proceedings of the Institution of Mechanical Engineers. 1897;52(I):31-100. http://dx.doi.org/I0.1243/PIME_PROC_I897_052_009_02.

2 Kayser FX, Patterson JW. Sir William Chandler Roberts-Austen. His role in the development of binary diagrams and modern physical metallurgy. Journal of Phase Equilibria. 1998; I9(I): I I- I8. http://dx.doi.org/I0. I007/BF029047I8.

3 Schmid-Fetzer R. Phase diagrams: the beginning of wisdom. Journal of Phase Equilibria and Diffusion. 20I4;35:735760.

4 Kaufman L, Bernstein H. Computer calculations of phase diagrams. New York: Academic Press; 1970.

5 Lukas HL, Fries SG, Sundman B. Computational thermodynamics: the calphad method. Cambridge: Cambridge University Press; 2007.

6 Cao W, Chen S, Zhang F, Wu K, Yang Y, Chang YA, et al. PANDAT software with PanEngine, PanOptimizer and PanPrecipitation for multi-component phase diagram calculation and materials property simulation. Calphad. 2009;33(2):328-342. http://dx.doi.org/10.1016/j.calphad.2008.08.004.

7 Andersson JO, Helander T, Höglund L, Shi P, Sundman B. Thermo-Calc \& DICTRA, computational tools for materials science. Calphad. 2002;26(2):273-312. http://dx.doi.org/I0.1016/S0364-5916(02)00037-8.

8 Bale CW, Bélisle E, Chartrand P, Decterov SA, Eriksson G, Hack K, et al. FactSage thermochemical software and databases — recent developments. Calphad. 2009;33(2):295-3 I I. http://dx.doi.org/I0.1016/j.calphad.2008.09.009.

9 Luo AA, Fu P, Peng L, Kang X, Li Z, Zhu T. X., Z. Li, T. Zhu, "Solidification microstructure and mechanical properties of cast magnesium-aluminum-tin alloys. Met. Mater. Trans. 20I2;43A(I):360-368. http://dx.doi.org/10.1007/s I I66I$01 \mathrm{I}-0820-\mathrm{y}$.

10 Gröbner J, Schmid-Fetzer R. Key issues in a thermodynamic Mg alloy database. Metallurgical and Materials Transactions. A, Physical Metallurgy and Materials Science. 2013;44(7):29/8-2934. http://dx.doi.org/I0.1007/ sI|66|-0I2-I483-z.

I I Schmid-Fetzer R, Andersson D, Chevalier PY, Eleno L, Fabrichnaya O, Kattner UR, et al. Assessment techniques, database design and software facilities for thermodynamics and diffusion. Calphad. 2007;3 (I):38-52. http://dx.doi. org/10.1016/j.calphad.2006.02.007.

12 Gröbner J, Kozlov A, Schmid-Fetzer R, Easton MA, Zhu S, Gibson MA, et al. Thermodynamic analysis of as-cast and heat treated microstructures of Mg-Ce-Nd alloys. Acta Materialia. 20II;59(2):6I3-622. http://dx.doi.org/I0.I0I6/j. actamat.2010.09.066.

13 Gröbner J, Hampl M, Schmid-Fetzer R, Easton MA, Zhu SM, Gibson MA, et al. Phase analysis of Mg-La-Nd and Mg-La-Ce alloys. Intermetallics. 20I2;28:92-I0I. http://dx.doi.org/I0.10I6/j.intermet.20I2.04.0I2.

14 Gröbner J, Schmid-Fetzer R. Thermodynamic modeling of the Mg-Ce-Gd-Y system. Scripta Materialia. 2010;63(7):674-679. http://dx.doi.org/10.1016/j.scriptamat.2010.01.035.

I5 Scheil E. Bemerkungen zur Schichtkristallbildung. Zeitschrift fur Metallkunde. 1942;34:70-72. 
I6 Hänzi AC, Dalla Torre FH, Sologubenko AS, Gunde P, Schmid-Fetzer R, Kuehlein M, et al. Design strategy for microalloyed ultra-ductile magnesium alloys. Philosophical Magazine Letters. 2009;89(6):377-390. http://dx.doi. org/I0. I080/09500830902960I25.

17 Cao G, Kou S. Hot tearing of ternary Mg-Al-Ca Alloy castings. Metallurgical and Materials Transactions A, Physical Metallurgy and Materials Science. 2006;37(I2):3647-3663. http://dx.doi.org/10. I007/sI I66I-006-I059-x.

18 Djurdjevic MB, Schmid-Fetzer R. Thermodynamic calculation as a tool for thixoforming alloy and process development. Materials Science and Engineering A. 2006;4I7(I-2):24-33. http://dx.doi.org/10.1016/j. msea.2005.08.227.

19 Cao G, Zhang C, Cao H, Chang YA, Kou S. Hot-tearing susceptibility of ternary Mg-Al-Sr alloy castings. Metallurgical and Materials Transactions. A, Physical Metallurgy and Materials Science. 2010;4I (3):706-716. http://dx.doi. org/I0.1007/s I | 66 I-009-0134-5.

20 Cao G, Kou S. Predicting and reducing liquation-cracking susceptibility based on temperature vs. fraction solid. Welding Journal. 2006;85:9-18.

2I Zhang C, Cao W, Chen S-L, Zhu J, Zhang F, Luo A, et al. Precipitation simulation of AZ9I alloy. Journal of Metals. 2014;66(3):389-396.

22 Easton MA, Gibson MA, Qiu D, Zhu SM, Gröbner J, Schmid-Fetzer R, et al. The role of crystallography and thermodynamics on phase selection in binary magnesium-rare earth (Ce or $\mathrm{Nd}$ ). Alloys. Acta Materialia. 2012;60(I I):4420-4430. http://dx.doi.org//0.10 I6/j.actamat.2012.04.039.

Received: 18 Jan. 2016

Accepted: 19 Jan. 2016 